\title{
"Imperfect hips". Two clinical types of insufficiency of hip joints. Possibility of prophylaxis by physiotherapeutic methods
}

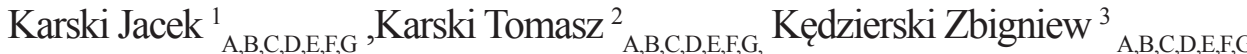 \\ ${ }^{1}$ Paediatric Orthopaedic and Rehabilitation Department of Medical University of Lublin, Poland, \\ 2 Vincent Pol University of Lublin, Poland
}

\section{Summary}

The article presents problems of pain syndrome as the first sign of illness of the left hip in the context of not fully cured dysplasia, and as the problem of the right hip as the result of the syndrome of permanent standing 'at ease' on the right leg. Hip dysplasia occur in the "Syndrome of Contractures and Deformities" (SofCD), in majority the left sided SofCD. The pain syndrome in the left hip is the first sign of the illness originating in the not-fully cured dysplasia. The material constitutes of 552 patients with "hip pain syndrome" examined during the years $1995-2013$. The age of patients is from 16 to 85 . The radiological sings are connected with incorrect congruency of the femoral head in acetabulum. The article physiotherapeutical exercises (kinesiotherapy), as well as exercises performed in geothermal waters.

Key words: coxarthrosis, prophylaxis treatment, hip dyspalsia

\section{Introduction}

The article is based on the material collected by the authors in the Paediatric Orthopaedic and Rehabilitation Department Medical University and the Out-Patient Clinic in the years 1995 - 2013 as well as in the Out-Patient Clinic of the Military Hospital in Lublin in the years 2009 - 2014. Both the clinical and radiological features of hips and the literature discussing methods of prevention and conservative treatment have been presented. The article presents problems of pain syndrome as the first sign of illness of the left hip in the context of not fully cured dysplasia, and as the problem of the right hip as the result of the syndrome of permanent standing 'at ease' on the right leg.

\section{Newborns, babies and toddlers with hips problems}

Hip dysplasia can occur in the "Syndrome of Contractures and Deformities" (SofCD) when the foetus had not a sufficient space in the uterus. In the majority of cases we observe the left sided SofCD (Fig. 1, 2a, 2b) and dysplasia of the left hip also is a very common problem. (Fig. 3). The treatment of hip dysplasia should begin as early as possible, the best period is 1 st - 3rd weeks of life (Ortolani [1], Vizkelety [2], Bjerkreim [3], Papp [4], Dega [5], Szulc [6], Piątkowski [7], Karski J. [8, 9], Karski T. [10]). During the time of this early treatment proper nurseling with full abduction and big flexion (120 degree) of hips is very important. The application of orthopaedic devices such as Frejka pillow, Weickert's trousers or other "abduction devices" (Fig. 4a, 4b, 4c, 4d) is frequently also recommended. Only such early treatment of hips can protect against "imperfect hips" and against future arthrosis.

Early treatment of hip dysplasia or even hip dislocation gives the best results (Fig. 5a, 5b) [2, 3, 6, 11, 12, 13].

The definition of the "imperfect hips"

In our orthopaedic practice, we encounter patients presenting various symptoms such pain, limited movement of hips, and temporary limping. The X-ray examination

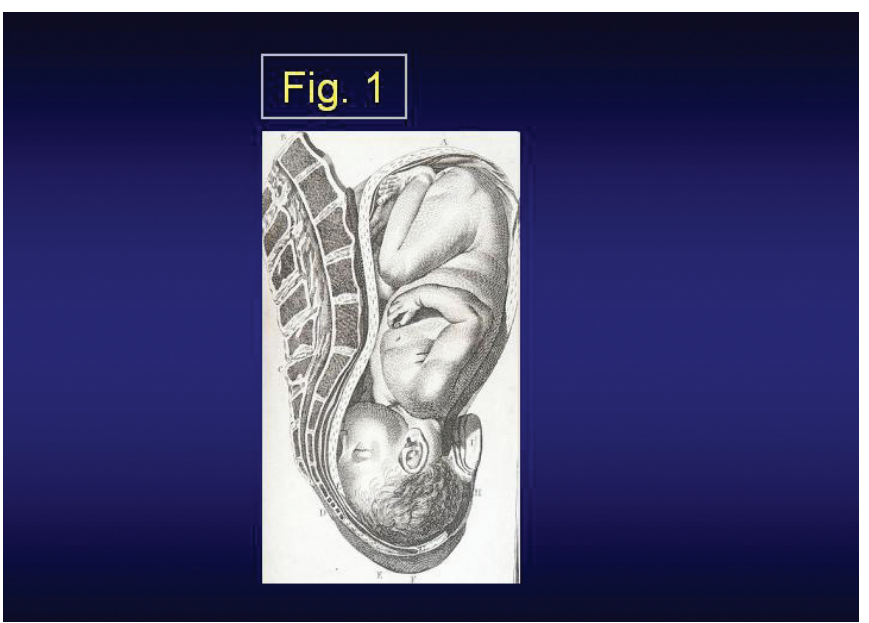

Fig. 1 Cephalic presentation of foetus is most common during pregnancy. In $97 \%$ pregnancies the foetus is on the left side of the uterus with the head down. When the space in the uterus is not sufficient- "syndrome of contractures and deformities" can develop. Consequently, dysplasia of the hip - more frequently on left side can appear. Picture taken from the Internet. 


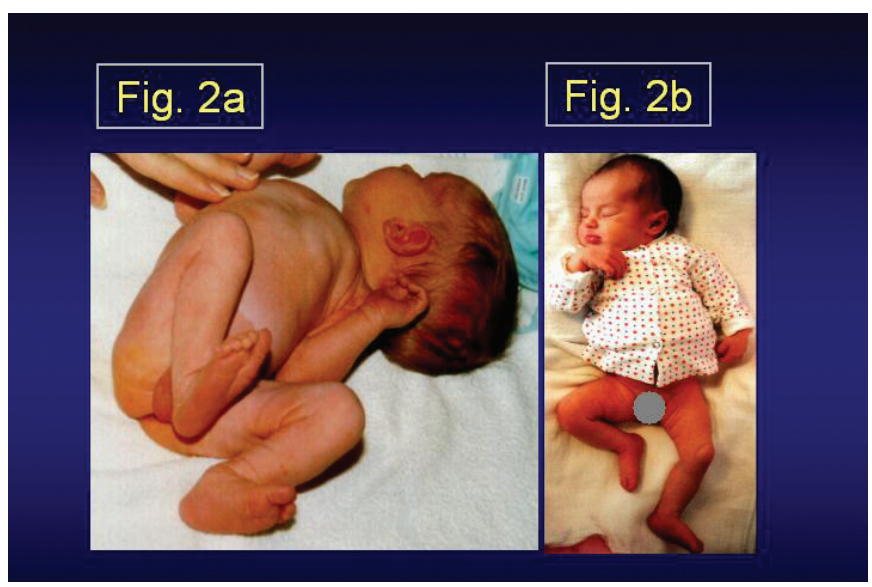

Fig. 2a, 2b-Newborn (2a). Deformations present in the „syndrome of seven contractures and deformities”: wry neck, infantile scoliosis, valgus deformity of feet. Infant (2b) - adduction contracture of the left hip. Danger of oncoming dysplasia of this hip.

shows "almost normal hip joints". Careful examination of their X-ray pictures shows normal Wiberg angle, normal CCD angle, normal AT angle and even good or almost good roof (covering of the femoral head) but the congruence of "femoral head in acetabulum" is not proper - the distance from the femoral head to bottom of acetabulum is much bigger than the distance of femoral head to the roof. Such hips are permanently overstressed during gait. The mathematical rule of the function of hip joints in such situation is provided below. The first symptom of "imperfect hips" is pain followed by full range of arthritic symptoms. The arthrosis of left hip is mostly connected with the primary hip dysplasia, not sufficiently treated in childhood (Fig. 6a, 6b, 7a, $7 \mathrm{~b})$. The arthrosis of the right hip is connected with "the syndrome of permanent standing 'at ease' on the right leg" over years (Fig. 8a, 8b, 9, 10a, 10b). The first symptoms of the "imperfect hips" appear at the age of $35-45$ (90\%). Only in few cases earlier, at the age of $16-25$ (10\%) $[3,8,10,13,14,15,16,17]$.

Material
The material constitutes of 552 patients with "hip pain syndrome" examined during the years 1995 2013. The age of patients is from 16 to 85 .

\section{Clinical symptoms of "imperfect hips"}

In the course of life adults tend to lose their abilities for abduction, internal rotation and extension of the hips. Some patients present such limitation of movements on left side / hip (30\%), others of right side / hip (70\%). The pain syndrome in the left hip is the first sign of the illness originating in the not-fully cured dysplasia. The symptoms in the right hip are the result of the syndrome of permanent standing 'at ease' on the right leg. The first symptoms of hip insufficiencies are: temporary pain - very often at the beginning of the day, before the first steps are made, and pain after a long walk or after physical activity. Patients occasionally present limping - in the initial period of the illnesses and this phenomenon is only temporary. The pain is usually located in inguinal region, sometimes on the lateral side of the hip, and in some patients in the lateral upper part

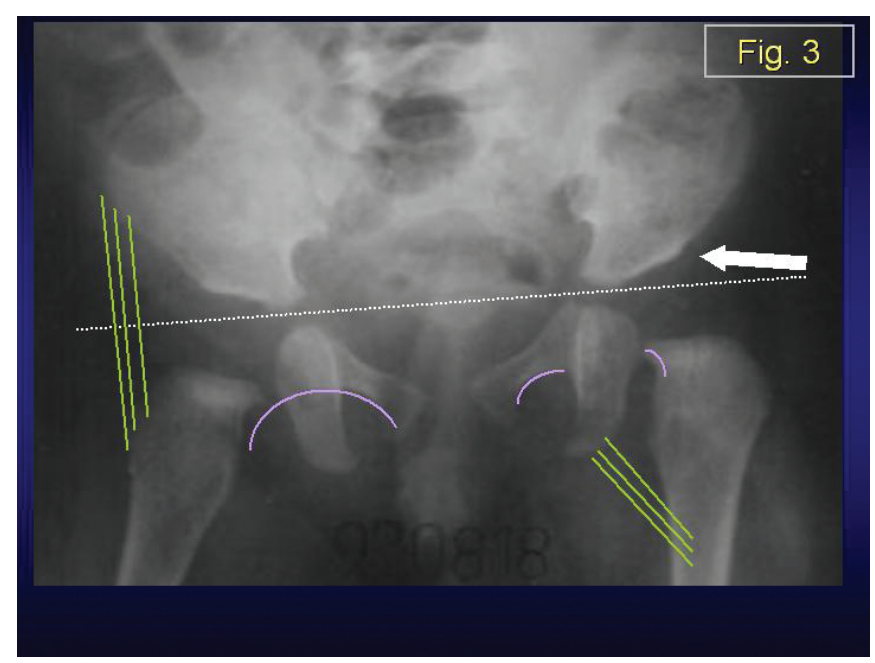

Fig. 3 The child with adduction contractures of the left hips. Arrow shows dysplastic roof. The child was not treated before the first orthopaedic examination. It was also no properly taken care of, and no orthopaedic devices were used. Simultaneously the abduction contracture of the right hip is observed. 


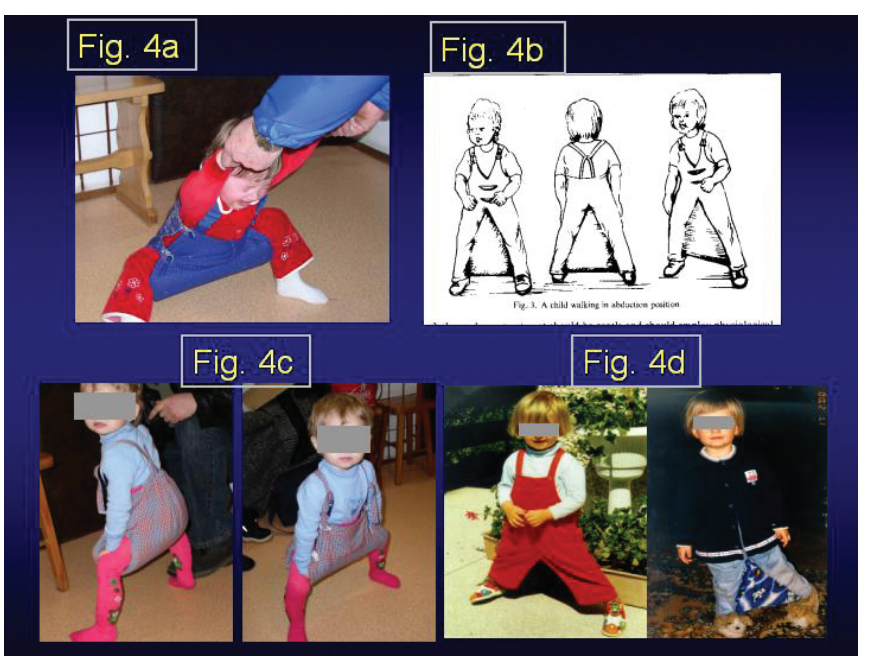

Fig. 4a, 4b, 4c, 4e - functional abduction therapy of the hip dysplasia using the Weickert's trousers or abduction triangle made from spongy material.

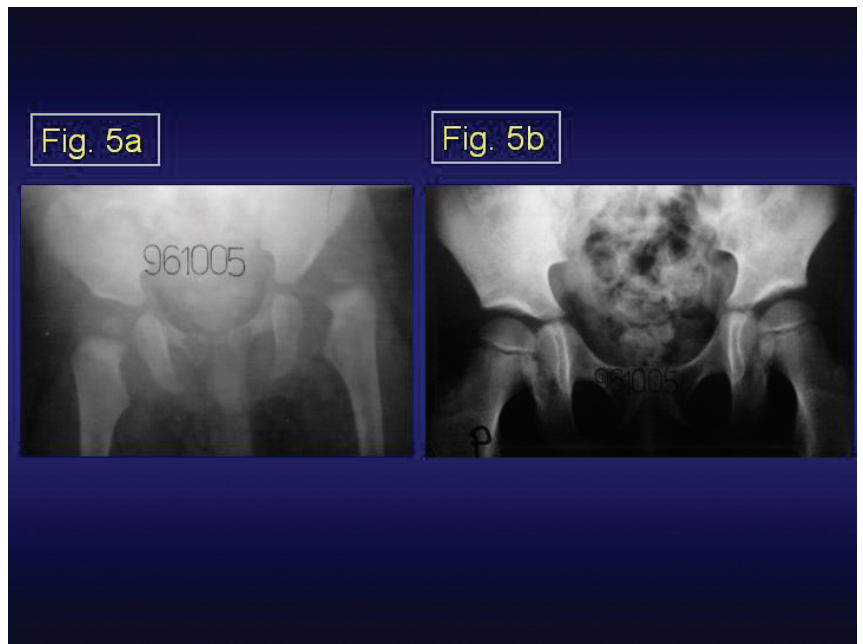

Fig. 5a, 5b - child Maciej B. born 5th October 1996. Fig. 5a - dislocated left hip. After conservative reduction, functional abduction therapy using the Weickert's treasures. Fig. $5 \mathrm{~b}$ - the result after 2 years of treatment.

of the femur.

\section{Radiological symptoms of “imperfect hips"}

As mentioned above - the radiological sings are connected with incorrect congruency of the femoral head in acetabulum.

There are cases that even when all angles and the shape of the proximal end of femur is proper and correct, the hip joint can still be incorrect if the shape of the femur head and the shape of acetabulum are not situated as parallels. It means that the distance of the bottom of acetanulum to the head is bigger than the distance between the head and roof (Fig. 9, 10a, 10b).

The prophylaxis and treatment of "imperfect hips" by

\section{physiotherapies methods}

The aim of the treatment and prophylaxis (in many cases treatment and prophylaxis mean the same) is to restore the full movement of hips. The goal is also to permanently change the direction (line) of load during standing and during gait. The article presents research conducted in 25 years of physiotherapeutical exercises (kinesiotherapy), as well as exercises performed in geothermal waters, the best in Hungary (Fig. 11a, 11b, 11c).

\section{Discussion}

Many authors mentioned that dysplasia should be treated completely $[1,2,3,4,5,6,7,8,10]$. Otherwise it can lead to problems. Not only narrow roof is important but congruential of femoral head towards acetabulum is very important too. The shapes of both must be parallel. Radiological analysis show it in a few papers already $[12,13,14,15,17]$. Our observation would like 


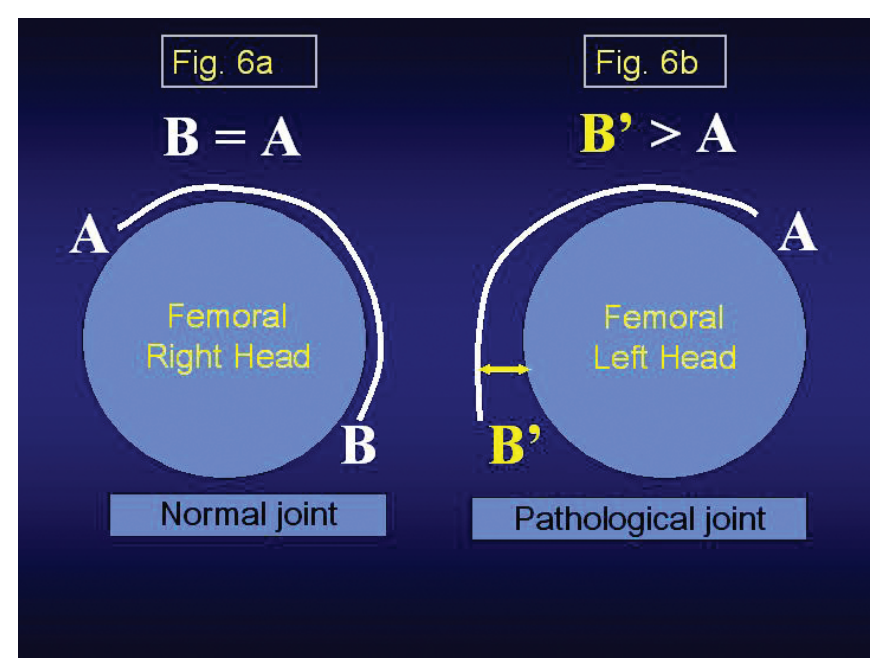

Fig. $6 \mathrm{a}, 6 \mathrm{~b}$ - normal right hip. Fig. $6 \mathrm{~b}$ - pathological left hip. The distance from the head to the bottom is bigger than the distance to roof. In such „imperfect hips”, excessive load is placed while walking which causes pain and later arthrosis may develop.

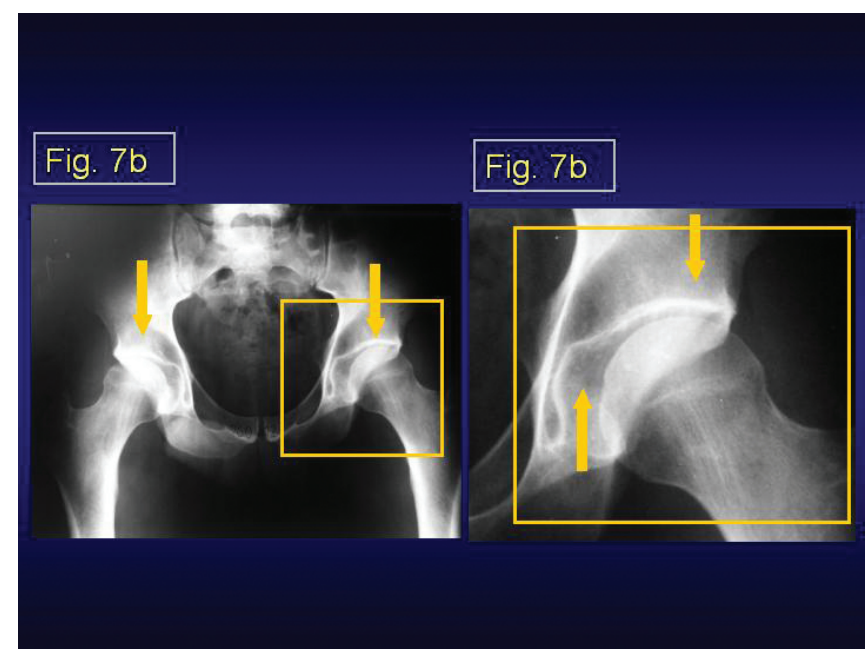

Fig. 7a, $7 \mathrm{~b}$ - both sided ,imperfect hips”. Fig. 7b - shows a bigger distance from the head to the bottom of acetabulum than to the roof (arrow). Overstress of both hips (arrows). Patient with pain, more severe on the left side.

to stress that it is very important and proper exercise, right positions can recover movements of the hip joint and reduce pain. The necessity of hip replacement moving away.

\section{Conclusions.}

1/ The hips in newborns, babies and toddlers must be fully cured that is in $100 \%$ (restitutio ad integrum),

2/ Not-fully treated hips, over the period of time will worsen (imperfect hips),

3 / It is important to remember about the syndrome of permanent standing 'at ease' on the right leg as the cause of arthrosis of the right hip

4/ In the course of treatment, in spite all physiotherapy and rehabilitation methods, the most important factor is to change the axis of load of both hips in daily life. $5 /$ In prophylaxis and therapy, we advice changes in the manners of standing, walking, sitting and sleeping.
9/ Such proper physiotherapy can protect against arthrosis for many years.

\section{References:}

1. Ortolani M. Detecting Dislocated Hip. Lancet Volume: 1 Issue: 8062 Pages: 506-507 Published: 1978

2. Vizkelety, T.: Wspolczesne problemy wrodzonego zwichniecia i dysplazji biodra. [Current problems of congenital hip dislocation and dysplasia]. Chirurgia narzadow ruchu i ortopedia polska 1981. Volume: 46 Issue: 5 Pages: 429-34

3. Bjerkreim I. Secondary Dysplasia And Osteoarthrosis Of Hip-Joint In Functional And In Fixed Obliquity Of Pelvis. Acta Orthopaedica Scandinavica Volume: 45 Issue: 6 Pages: 873-882 Published: 1974 4. $\quad$ Papp K., Rigo J., Szepesi K., Meszaros T., Or- 


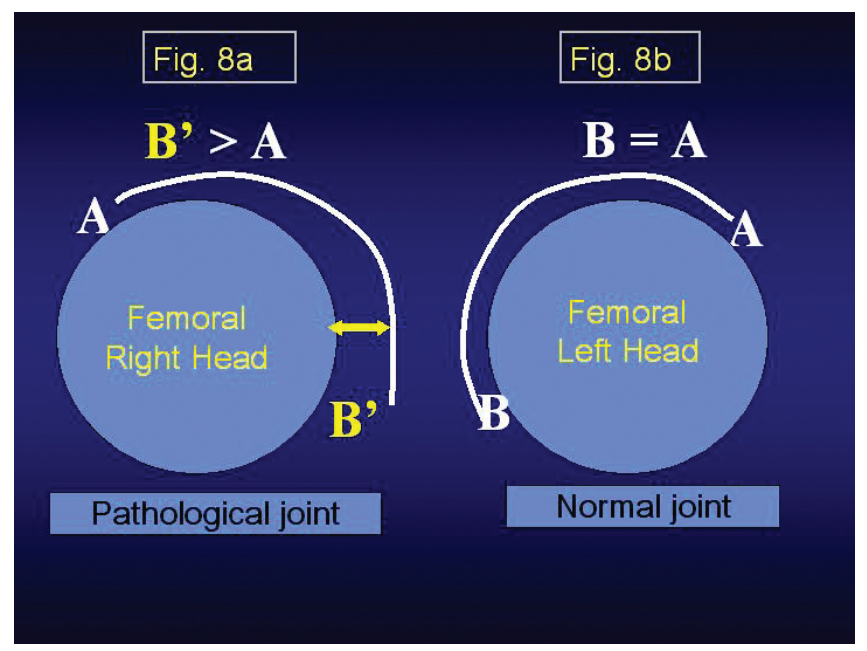

Fig. 8a, 8b - pathological right hip as the result of the syndrome of standing 'at ease' on the right leg. In the right hip the distance from the head to the bottom is bigger than to the roof. In such an „imperfect hip” during gait overstress causing pain is observed, which later may lead to arthrosis. On Fig. 8b - normal left hip.

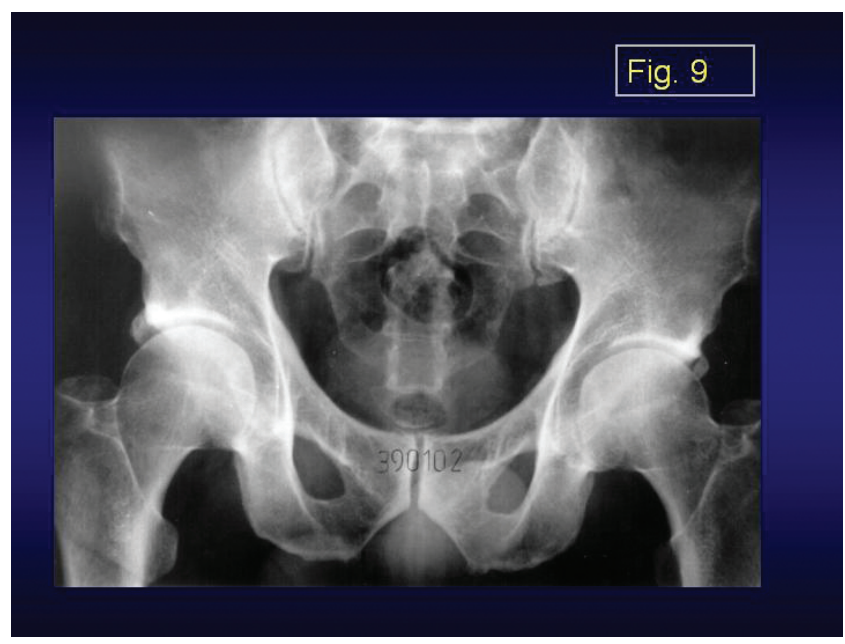

Fig. 9 - Patient during first examination is 50. History nr 390102. Both sided „imperfect hips”. The problem is bigger in the right joint as result of the ssyndrome of standing 'at ease' on the right leg. Patient reports pain and difficulties in walking. After introducing of prophylactic rules hips received full movement and walking was without pain.

tolani M., Vizkelety T., Bjerkreim I. in Book with material from „Symposium - latest achievements in orthopaedics and in paediatric orthopaedics. Prophylactic program important in 'Bones and Joint Decade 2000 2010” / 40 lat Katedry Ortopedii Dziecięcej Uniwersytetu Medycznego w Lublinie (1070 - 2009/2010), Lublin, 2009, $133-223$

5. Dega W. Badania $\mathrm{z}$ dziedziny etiologii wrodzonego zwichnięcia biodra. Chir. Narz. Ruchu, 1932, 144

6. Szulc W. Badania doswiadczalne nad etiologia wrodzonego zwichniecia stawu biodrowego. [Experimental study on the etiology of congenital hip dislocation]. Chirurgia narzadow ruchu i ortopedia polska Volume: 35. Issue: 1. Pages: 1-6. Published: 1970

7. Piątkowski S. (red.) - Ortopedia, traumatologia i rehabilitacja narządów ruchu. Państwowy Zakład wydawnictw Lekarskich. 1990, 160-187

8. Karski J., Karski T., Kałakucki J., Wojtowicz -
Minimal incongruence of the hip joint as the biomechanical cause of overloading of the femoral head. Explanation of reasons of the "painful hip" at youth and adults and development of coxarthrosis incipiens. Magyar. Traumatol. Ortop. 2003 Suppl. p. 80-81.

9. Karski J., Kałakucki J., Karski T., Krzyszof Wójtowicz - Incongruence of hip joint in treated and untreated persons with $\mathrm{DDH}$ in the baby period. Contribution to the knowledge of the very early stage of hip arthrosis (coxarthrosis incipiens). (Niezborność stawu biodrowego u osób leczonych $\mathrm{w}$ dzieciństwie z powodu wrodzonej dysplazji biodra i u osób nieleczonych. Przyczynek do wiedzy o wczesnych fazach koksartrozy (coxarthrosis incipiens).). Annales UMCS Sect. D 2005 vol. $60 \mathrm{nr}$ 1, s. 32-39

10. Karski Tomasz, Jacek Karski, Jarosław Kałakucki - Minimal incongruence of the hip joint at youth and adults treated and not-treated because of DDH in 


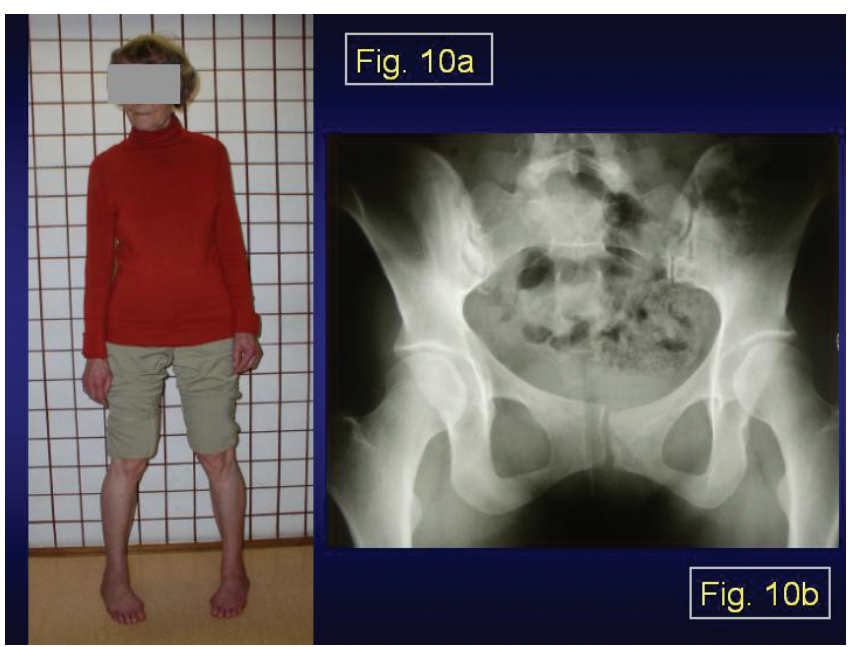

Fig. 10a, 10b - Patient aged 69. History nr 410214. Both sided „imperfect hips” (11b). The problem is bigger in the right joint as the result of syndrome of standing 'at ease' on the right leg. The patient complains of pain and difficulties in walking. In the picture on left - there is therapeutic standing in abduction in internal rotation (11a).

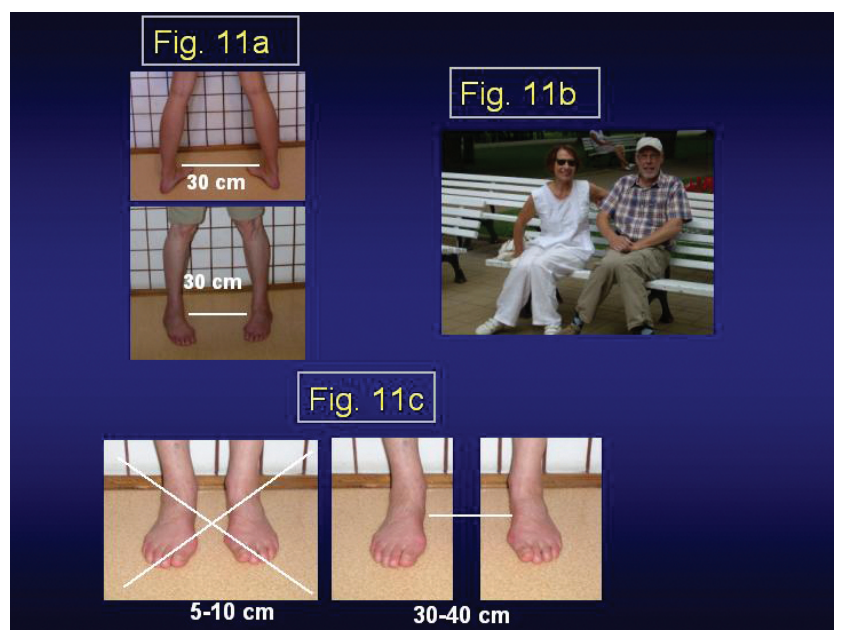

Fig. 11a, 11b, 11c Physiotherapy of imperfect hips. Standing in abduction and in internal rotation (11a), Sitting in internal rotation (11b), Walking in abduction $30-40 \mathrm{~cm}$, Sleeping in abduction and flexion of hip. (11c)

baby period. W: Second Annual International Conference SICOT/SIROT 2003. Cairo, September 10-13, 2003. Abstr, [b. pag.] SFS8-HDelaunay S, Dussault RG, Kaplan PA, Alford BA. Radiographic measurements of dysplastic adult hips. Skeletal Radiol 1997;26:75-81.

11. Fredensborg N, Nilsson B. The joint space in normal hip radiograms. Radiology 1978;126:325-6.

12. Lanyon P, Muir K, Doherty S, Doherty M. Age and sex differences in hip joint space among asymptomatic subjects without structural change : implications for epidemiologic studies. Arthritis Rheum 2003;48:1041-6.

13. Lequesne M, J Malghem, E Dion: The normal hip joint space: variations in width, shape, and architecture on 223 pelvic radiographs. Ann Rheum. /France/ Dis. 2004:63:11451151.

14. Dunn P. Congenital postural deformities: further perinatal associations. Proc. R. Soc. Med 1974;67:1174-8.

15. Roach KE, Persky V, Miles T, Budiman-Mak E. Biomechanical aspects of occupation and osteoarthritis of the hip: a case-control study. J. Rheumatol. 1994;21:2334-40.
16. Rosegger H; Steinwendner G, Transverse fetal position syndrome a combination of congenital skeletal deformities in the newborn infant. (German) Pädiatrie und Pädologie [Padiatr Padol], ISSN: 0030-9338, 1992; Vol. 27 (5), pp. 125-7; Publisher: Springer;PMID:1437228;

Spector T. Radiographic criteria for epidemiologic studies of osteoarthritis. J Rheumatol 1995;22 (suppl 43):46-7.

17. Thelin A, Jansson B, Jacobsson B, Strom H. Coxarthrosis and farm work; a case-referent study. Am J. Ind. Med. 1997;32:497-501.

Acknowledgement: We would like to express our thanks words to MA Katarzyna Karska for correction of English in this paper.

\section{Correspondence address:}

Jacek Karski MD PhD

Harcerska 35

20-805 Lublin

Poland

jkarski@vp.pl

tmkarski@gmail.com 